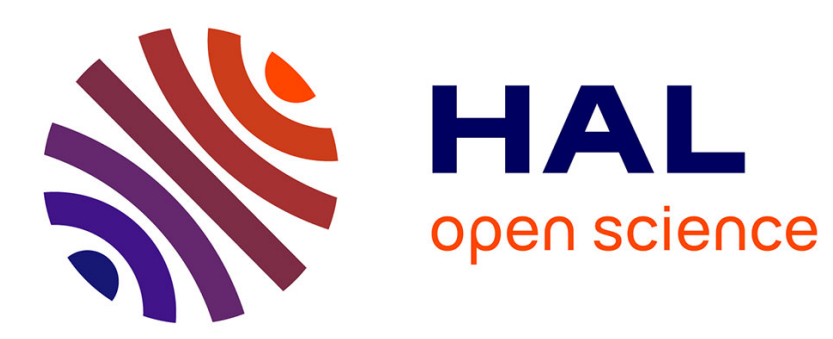

\title{
Current-Mode Power Converter for Radiation Control in DBD Excimer Lamps
}

\author{
Rafael Diez, Hubert Piquet, Marc Cousineau, Sounil Bhosle
}

\section{To cite this version:}

Rafael Diez, Hubert Piquet, Marc Cousineau, Sounil Bhosle. Current-Mode Power Converter for Radiation Control in DBD Excimer Lamps. IEEE Transactions on Industrial Electronics, 2012, 59 (4), pp.1912-1919. 10.1109/TIE.2011.2126536 . hal-01425191

\section{HAL Id: hal-01425191 https://hal.science/hal-01425191}

Submitted on 3 Jan 2017

HAL is a multi-disciplinary open access archive for the deposit and dissemination of scientific research documents, whether they are published or not. The documents may come from teaching and research institutions in France or abroad, or from public or private research centers.
L'archive ouverte pluridisciplinaire HAL, est destinée au dépôt et à la diffusion de documents scientifiques de niveau recherche, publiés ou non, émanant des établissements d'enseignement et de recherche français ou étrangers, des laboratoires publics ou privés. 


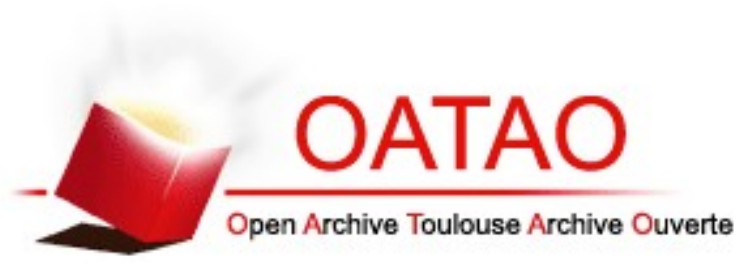

\section{Open Archive Toulouse Archive Ouverte (OATAO)}

OATAO is an open access repository that collects the work of Toulouse researchers and makes it freely available over the web where possible.

This is an author-deposited version published in: http://oatao.univ-toulouse.fr/ Eprints ID: 17319

To link to this article : DOI: 10.1109/TIE.2011.2126536

URL : http://dx.doi.org/10.1109/TIE.2011.2126536

To cite this version: Diez Medina, Rafael and Piquet, Hubert and Cousineau, Marc and Bhosle, Sounil Current-Mode Power Converter for Radiation Control in DBD Excimer Lamps. (2012) IEEE Transactions on Industrial Electronics, vol. 59 ( $\left.\mathrm{n}^{\circ} 4\right)$. pp. 1912-1919. ISSN 0278-0046

Any correspondence concerning this service should be sent to the repository administrator: staff-oatao@listes-diff.inp-toulouse.fr 


\title{
Current-Mode Power Converter for Radiation Control in DBD Excimer Lamps
}

\author{
Rafael Díez, Member, IEEE, Hubert Piquet, Marc Cousineau, Member, IEEE, and Sounil Bhosle, Member, IEEE
}

\begin{abstract}
A pulsed current-mode converter specifically designed for the supply of dielectric barrier discharge excimer lamps is proposed in this paper. The power supply structure is defined on the basis of causality criteria that are justified by the structure of the lamp model. The converter operation is studied, and its design criteria are established using state-plane analysis. This converter, operating in discontinuous conduction mode, controls directly both the amplitude and the duration of the emitted ultraviolet (UV) pulses. Experimentally, the UV radiation is demonstrated to be proportional to the current injected into the gas, and the degrees of freedom offered by the control of the supply are shown to be very efficient for the active control of the UV power.
\end{abstract}

Index Terms-Current control, dielectric barrier discharge (DBD), power conversion, ultraviolet generation.

\section{INTRODUCTION}

D IELECTRIC BARRIER DISCHARGES (DBDs) and their applications are spread out to numerous domains such as surface treatment, decontamination, semiconductor fabrication, and lighting [1]-[4]. A particular use of these discharges is ultraviolet (UV) ray generation [5]-[7], which originally was, and still is, achieved in gas mixtures containing considerable quantities of mercury, which is a contaminant element [8]. An alternative form to produce UV radiation, reducing the negative environmental impact, consists of the excitation of gas mixtures containing a noble gas, $(\mathrm{Xe}, \mathrm{Kr})$ and a halogen gas $(\mathrm{Cl}, \mathrm{Br})$ [5]. The electric discharge installed in the gas produces nonstable molecules called excimers (or exciplex if more than one element is part of the molecule). The wavelength emitted, when this molecule returns to its ground state, depends only on the gas mixture, e.g., $\mathrm{XeCl}$ and $\mathrm{KrCl}$ produce 308 and $222 \mathrm{~nm}$, respectively [9].

Excimer sources present other advantages with respect to mercury discharges, which are higher power density and narrow-band spectrum. These characteristics increase the efficiency of the target process, with a reduction of the exposition time or the expansion of the radiated area or volume [8], [10].

R. Diez is with the Department of Electronics, Pontificia Universidad Javeriana, Bogotá 110311, Colombia (e-mail: rdiez@ javeriana.edu.co).

$\mathrm{H}$. Piquet and M. Cousineau are with Laboratoire PLAsma et Conversion d'Energie (LAPLACE), 31071 Toulouse, France (e-mail: Hubert.Piquet@ Laplace.univ-tlse.fr; Marc.Cousineau@Laplace.univ-tlse.fr).

S. Bhosle is with the LED Engineering Development, 31100 Toulouse, France (e-mail: sounil.bhosle@led-development.fr).



Fig. 1. Geometry of a DBD lamp with coaxial configuration.

Within the DBD lamps suited for UV generation, the most common configuration is that illustrated in Fig. 1: the gas mixture is confined between two glass walls (two dielectric barriers), and these avoid contact of the gas with the metallic electrodes. This configuration enhances the lifetime of lamps, as it prevents the transition to arc regime of the discharge and the contamination of the gas mixture with electrode residues [11].

This promising solution for UV generation and associated applications requires specific studies concerning the interaction between the DBD and its associated power supply [12]-[15]. In this paper, the following approach is respected to establish the choice of a well-suited supply mode:

In Section II, the basis of lamp modeling is reviewed. In Section III, the results of modeling are applied to establish, applying causality criteria, that current mode is the best way to supply this load. In Section IV, the converter topology that implements a direct control of the lamp current is presented. Finally, in Section V, the degrees of freedom (DOFs) offered by the converter are experimentally exploited to search the most convenient operating conditions, regarding the electric to UV conversion efficiency of the DBD excimer lamp.

\section{Electrical Model of DBD Excilamps}

For nonclassical applications such as gas discharges, it is important to model the behavior of the load and to identify the right way by which it must be supplied, before starting to propose the converter to be used [16]-[19].

In the present case, the DBD lamp can be modeled using its physical structure, which is shown in Fig. 1. If the current path is followed from the positive to the negative electrode of the power supply, every physical element can be translated into an electric component of the equivalent circuit shown in Fig 2(a). First, the lamp current $i_{\text {lamp }}$ goes into the internal barrier represented by the capacitor $C_{\text {int }}$; afterward, it flows through the gas, and finally, the current returns to the external 


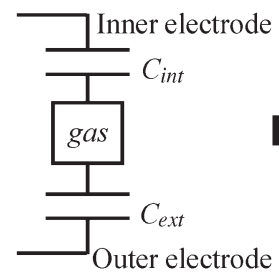

(a)

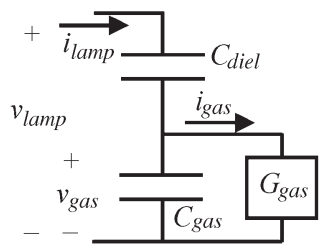

(b)
Fig. 2. Equivalent electric model of the DBD lamp. (a) Interpretation of each physical component. (b) Reduction of the circuit.

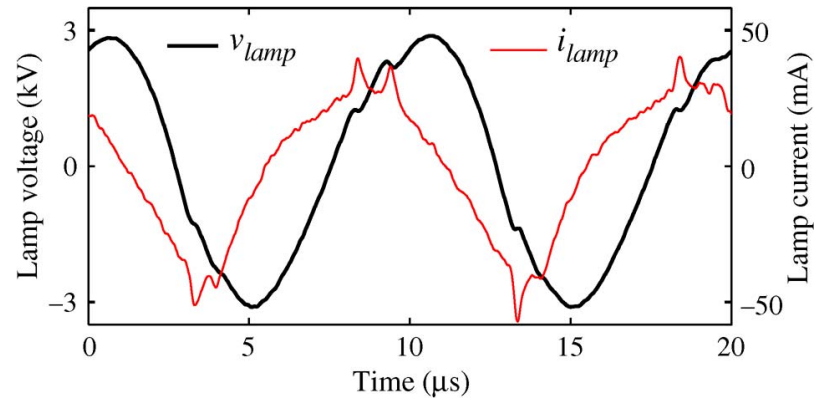

Fig. 3. Lamp voltage and current showing the capacitive nature of the lamp.

electrode crossing the external barrier, which is symbolized with capacitor $C_{\text {ext }}$.

In Fig 2(b), the two capacitances corresponding to the dielectric barriers are simplified to obtain the series equivalent capacitance $C_{\text {diel }}$. The gas behavior is dependent on the gas voltage $v_{\text {gas }}$. If this is less than the breakdown voltage $V_{\mathrm{th}}$, it presents a dielectric nature; consequently, it is represented by the gas capacitance $C_{\text {gas }}$. When the gas voltage reaches the $V_{\mathrm{th}}$ breakdown value, the discharge is established, and the gas is characterized as a variable conductance

$$
\begin{aligned}
\frac{d G_{\text {gas }}}{d t}=K_{1} \cdot\left[1+\exp \left(\frac{V_{\mathrm{th}}-\left|v_{\text {gas }}\right|}{\Delta V}\right)\right]^{-1} \\
\quad+K_{2} \cdot\left|i_{\text {gas }}\right|-K_{3} \cdot G_{\text {gas }}
\end{aligned}
$$

where $G_{\text {gas }}$ and $i_{\text {gas }}$ are the gas conductance and current, respectively, and $\Delta V, K_{1}, K_{2}$, and $K_{3}$ are constants. In the right-hand side of this equation, the first term is associated to the breakdown phenomenon, the second one is related to the production of conducting species, and the last one is the recombination term presenting a first-order decay of the conductance when the gas current cancels.

The complete explanation of this model and the procedure to identify its parameters is found in [20].

The noticeable capacitive behavior of this DBD is confirmed experimentally in Fig. 3, where a classic sinusoidal-voltage source is applied to the lamp. Here, a big part of the obtained lamp current is a displacement current, leading $90^{\circ}$ from the imposed voltage. The conduction current responsible for the actual power transfer to the lamp is related only to the peaks out of the sinusoidal shape.

This electrical model of the DBD lamp is very useful in performing simulations and studying interactions with the power converter; it also makes possible computing immeasurable variables like the gas voltage, current, and conductance.



Fig. 4. Gas voltage versus gas current (computed quantities). Desired operating areas (gas current controlling the power in the discharge) are highlighted.

Specifically using this model, the voltage-current characteristic for the confined gas has been plotted from an experimental measurement, using a classic voltage source (see Fig. 3); the result is shown in Fig. 4. Note that the calculated gas voltage is almost constant for all the values of the calculated gas current.

The modeling of the DBD presented before states the mainly capacitive characteristic of the lamp. For this reason, a currentmode converter is preferred, instead of a classical voltage-mode supply. The detailed analysis of this choice is performed in the next section.

\section{Causality Considerations Defining the POWER SUPPLY}

For investigation purposes, DBD loads have been traditionally supplied using linear power amplifiers [21]-[23]. Nevertheless, there has been an effort in the power electronics field to find a better energy transfer with the implementation of switched-mode converters [23]-[27]. For the specific case of excimer lamps, the typical power supply presents a square-voltage waveform switching at several tens of kilohertz [28]-[30]. In this section, a comparison is developed between this typical voltage mode and the proposed current mode, using the electrical model developed in Section II.

\section{A. Classical Voltage-Mode Approach}

In the traditional voltage-mode power supply, the lamp voltage $\left(v_{\text {lamp }}\right)$, presenting a pulsed waveform, is imposed. As the lamp presents a capacitive nature (thus trying to force its own voltage), the current returned by the lamp $i_{\text {lamp }}$ displays sharp pulses resulting from a derivative law applied by the equivalent capacitance of the lamp. The typical waveforms can be observed in Fig. 5. As the internal gas voltage $v_{\text {gas }}$ in the operating area is almost constant (cf. Fig. 4), the current in the lamp can be approximated using

$$
i_{\text {lamp }}=C_{\text {diel }} \cdot \frac{d v_{\text {lamp }}}{d t}
$$

In this case, the voltage source produces a current flow in the gas if the voltage amplitude is greater than the breakdown voltage. Nevertheless, the duration and the peak value of current cannot be correctly controlled, because those values depend on the rising and falling slopes of the voltage waveform. In 




Fig. 5. Current impulsions in a classical voltage supply. The amplitude and duration of current cannot be controlled.

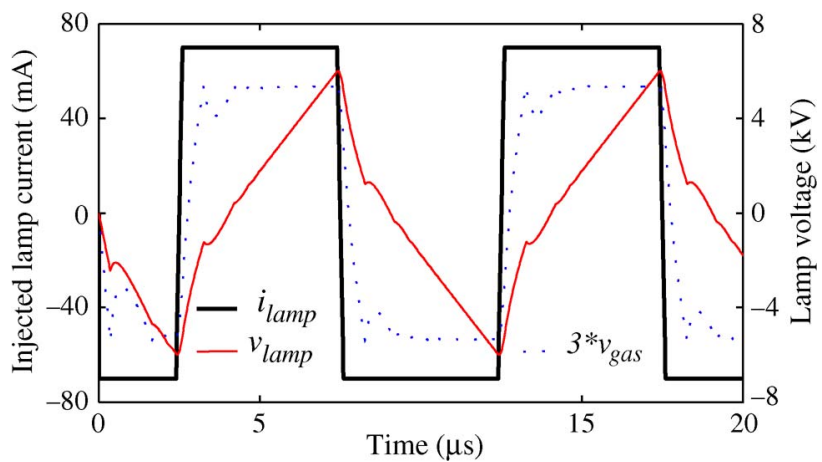

Fig. 6. Waveforms in a current-mode power supply. The gas voltage is almost constant once the breakdown is reached.

other words, these depend on the switching performances of the semiconductor devices.

In this type of structure, the energy sent to the lamp remains unknown at the design stage, because there is no certainty about the localization of the operating point within the desired area. Consequently, the only method to adjust the lamp power is changing the switching frequency.

\section{B. Current-Mode Approach}

In the proposed current-mode, a current is imposed to the lamp. Due to its capacitive nature (there is no opposition to the current), the voltage waveform is easily calculated using the electrical model by means of an integral law

$$
v_{\text {lamp }}=v_{\text {gas }}+\frac{1}{C_{\text {diel }}} \int i_{\text {lamp }} d t
$$

with, according to Fig. 4

$$
v_{\text {gas }} \cong V_{\mathrm{th}} \cdot \operatorname{sign}\left(i_{\text {gas }}\right)
$$

Fig. 6 illustrates a simulation where a square current waveform is imposed to the lamp. The lamp voltage is found using the electrical model previously developed. In the same simulation, it is possible to see that the gas voltage is almost constant (in absolute value) while the current is maintained, confirming that the desired operating area has been attained.

In the present case, the current imposed to the lamp flows through the gas once the gas voltage reaches the breakdown voltage $V_{\text {th }}$ (inflexion points of $v_{\text {lamp }}$ in Fig. 6). As a consequence, the operating point is controlled only by means of the

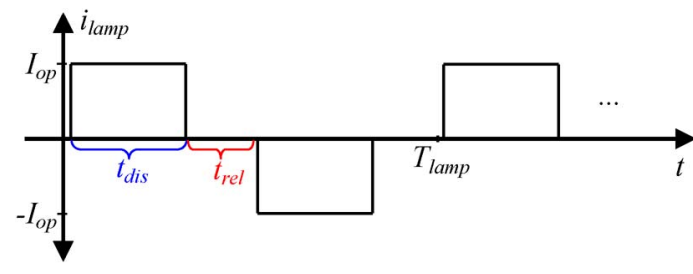

Fig. 7. Ideal lamp current waveform.

current amplitude (shifting right or left within the highlighted zone of Fig. 4).

In current-mode operation, the current imposed to the lamp must present a bidirectional zero-mean waveform, as the load behavior is mainly capacitive. If this condition is not fulfilled, the lamp voltage increases indefinitely and causes the damage of the power supply.

From this section, it is important to remind three points as conclusion.

1) Control of the discharge operating point must be accomplished, imposing the gas current by the intermediate of the lamp current.

2) Lamp current must be bidirectional in order to avoid the indefinitely increase of the lamp voltage, as the lamp is capacitive.

3) The electrical model allows the calculation of all the electrical variables at the design stage.

\section{POWER CONVERTER Synthesis}

According to the previous section, a converter capable of delivering the waveform shown in Fig. 7 would be ideal, in order to control the discharge operating point. An increase of the current amplitude $I_{\mathrm{op}}$ implies a right shifting of the operating point in Fig. 4 (for positive values).

In this waveform, the lamp current is intentionally zero during the relaxation time $t_{\text {rel }}$, because, a priori, it is necessary for the return of the excited species to their ground state [31].

For the particular case of the lamp studied in this paper, the following operating conditions are selected for the currentmode pulsed converter:

1) lamp peak current $<300 \mathrm{~mA}$;

2) selected operating frequency $50-100 \mathrm{kHz}$;

3) peak lamp voltage $<6 \mathrm{kV}$.

\section{A. Principle}

The design of the power supply is divided into two stages: 1) an inverter to change the current direction in the lamp each half-cycle and 2) a unidirectional current source $J$ working in discontinuous conduction mode (DCM) to guarantee the relaxation time.

The current inversion can be achieved with an H-bridge synchronized with the current source. However, as the lamp voltage reaches several kilovolts, a step-up transformer (with transformation ratio $n$ ) must be placed between the inverter and the lamp in order to reduce the semiconductor devices voltages. The nature of these switches will be explained later in Section IV-C. The transformer and the bridge can be reduced to 


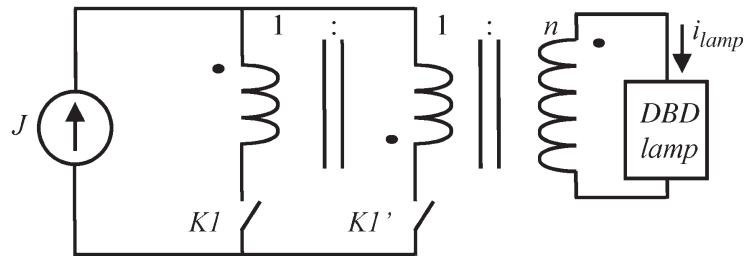

Fig. 8. Power supply concept including an adjustable current source $J$, the simplified H-bridge, and the step-up transformer.
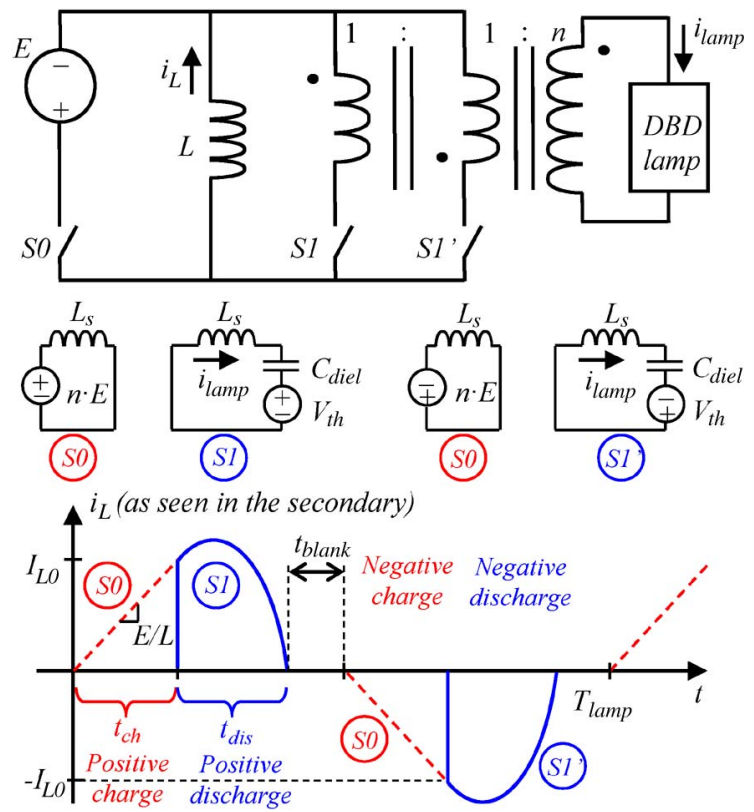

Fig. 9. Current-mode converter based on the buck-boost current source and its operating sequences. The equivalent circuits are as seen from the secondary side of the transformer.

obtain the schematic in Fig. 8 with only two ground-referenced switches.

The unidirectional current source $J$ can be taken from the classic boost or buck-boost configurations to assure the discontinuous-mode operation. In this paper, only the latter is studied.

\section{B. Current-Mode Converter Operation}

The buck-boost-based current converter, along with its possible sequences, is shown in Fig. 9 after reduction of the redundant switches. The equivalent circuits describing the operation of the converter are presented, as seen from the secondary side of the transformer. One entire switching period can be explained in three positive and three negative sequences.

1) Positive charge sequence: $S 0$ switch is turned on; the inductance current $i_{L}$ increases linearly from zero to a value $I_{L 0}$ controlled by input voltage source $E$, the inductance value $L$, and the charge time $t_{\mathrm{ch}}$. This sequence defines the amount of energy to be sent to the lamp during the next pulse, i.e.,

$$
\begin{aligned}
I_{L 0} & =\frac{E}{L} \cdot t_{\mathrm{ch}} \\
\text { Energy }_{\mathrm{c} t_{\mathrm{ch}}} & =\frac{1}{2} \cdot L \cdot I_{L 0}^{2} .
\end{aligned}
$$

2) Positive discharge sequence: $S 1$ switch is turned on, and S0 is turned off; the energy previously stored in the inductance is sent to the lamp, via the resonant circuit, associating $L_{s}$ ( $L$ seen from the secondary, with $\left.L_{s}=n^{2} \cdot L\right)$ and the dielectric capacitance $C_{\text {diel }}$. The gas voltage $v_{\text {gas }}$ is assumed to be constant and equal to $V_{\text {th }}$, in accordance with the modeling results.

The duration of this sequence is called the discharge time $t_{\mathrm{dis}}$ and is determined by the zero crossing of the inductance current.

3) Positive blanking time: All switches are turned off; the lamp current remains null, and the lamp voltage remains constant. The duration of this sequence $t_{\text {blank }}$ determines the operating frequency (6) and is part of the relaxation time, together with the positive charge sequence

$$
\begin{aligned}
f_{\text {lamp }} & =\frac{1}{2 \cdot\left(t_{\text {ch }}+t_{\text {dis }}+t_{\text {blank }}\right)} \\
t_{\text {rel }} & =t_{\text {ch }}+t_{\text {blank }} .
\end{aligned}
$$

4) Negative sequences: they are similar to the three positive sequences, using the $S 1^{\prime}$ switch, instead of $S 1$ in the discharge phase, to obtain a negative current in the lamp and to guarantee the zero-mean value of this waveform. Note that dc voltage source $E$ polarity is inverted in the third sequence in order to reflect the circuit (as seen from the secondary side of the transformer), which results in fourth sequence from the $S 1^{\prime}$ turn-on. The current in the lamp; flowing in the negative direction, the gas is sketched as a (negative) $-V_{\mathrm{th}}$ voltage source.

In this operating mode, the current-mode converter exhibits two DOFs to control the lamp power: the energy sent each halfperiod and the operating frequency, i.e.,

$$
P_{\text {lamp }}=2 \cdot f_{\text {lamp }} \cdot \text { Energy } @ \text { tch } .
$$

This converter also presents zero-current switching (ZCS) for all the three switches at turn-off; additionally, due to the DCM operation of the buck-boost converter, $S 0$ also turns on with a null current. These characteristics increase the efficiency of the system when compared to a voltage-mode source. Note that ZCS for $S 0$ at turn-off is achieved due to the switch used, which presents spontaneous turn-off characteristic; this event occurs as a consequence of $S 1$ or $S 1^{\prime}$ controlled turn-on. The implementation of this switch is detailed in Section IV-C.

Due to the resonant behavior of this converter during the discharge sequences, the entire analysis and dimensioning of the components can be done by means of the state-plane analysis, as shown in Fig. 10 [32], [33]. To draw this plane, the following normalization is used:

$$
\begin{aligned}
& x=\frac{v}{V_{\mathrm{th}}} \\
& y=\frac{i}{V_{\mathrm{th}}} \sqrt{\frac{L}{C_{\text {diel }}}}
\end{aligned}
$$



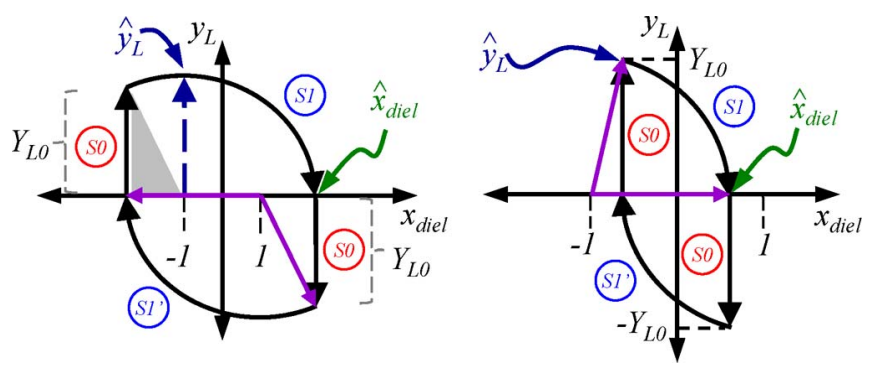

Fig. 10. State plane for the current-mode converter in steady state. Two possible solutions are obtained: the peak inductance current can be (left) greater than or (right) equal to $I_{L 0}$.

where $x$ and $y$ are the normalization for any voltage $v$ or current $i$, respectively. The normalized dielectric voltage $x_{\text {diel }}$ and the normalized inductance current $y_{L}$ correspond to the horizontal and vertical axes of the state plane, respectively.

The peak normalized voltage in the dielectric capacitance is found to be

$$
\hat{x}_{\text {diel }}=\frac{Y_{L 0}^{2}}{4}
$$

where $Y_{L 0}$ is the normalized current in the inductance at the end of the charge sequence. Hence, adding the constant gas voltage to this equation and "denormalizing," the peak voltage across the lamp gives

$$
\hat{v}_{\text {lamp }}=\frac{L \cdot I_{L 0}^{2}}{4 \cdot C_{\mathrm{diel}} \cdot V_{\mathrm{th}}}+V_{\mathrm{th}} .
$$

The peak current in the inductance depends on the following condition:

$$
I_{L 0}>2 \cdot V_{\mathrm{th}} \cdot \sqrt{\frac{C_{\text {diel }}}{L}} .
$$

If this condition is fulfilled, the state plane corresponds to the left side of Fig. 10. In this case, the peak inductance current and the discharge time are found with

$$
\begin{aligned}
\hat{i}_{L} & =\frac{I_{L 0}^{2} \cdot \sqrt{\frac{L}{C_{\text {diel }}}}}{4 \cdot V_{\mathrm{th}}}+V_{\mathrm{th}} \cdot \sqrt{\frac{C_{\text {diel }}}{L}} \\
t_{\mathrm{dis}} & =n \cdot \sqrt{L \cdot C_{\text {diel }}} \cdot\left[\pi-\arcsin \left(\frac{I_{L 0}}{\hat{i}_{L}}\right)\right] .
\end{aligned}
$$

In other case, the state plane corresponds to the right case of Fig. 10, and the following equations must be applied:

$$
\begin{aligned}
\hat{i}_{L} & =I_{L 0} \\
t_{\text {dis }} & =n \cdot \sqrt{L \cdot C_{\text {diel }}} \cdot \arcsin \left(\frac{I_{L 0}}{\hat{v}_{\text {lamp }}} \cdot \sqrt{\frac{L}{C_{\text {diel }}}}\right) .
\end{aligned}
$$

The (6)-(17) equations set is used to realize the converter design. The complete study of this converter and the corresponding one for the boost-based converter, which can exhibit unstable behavior, can be found in [34].
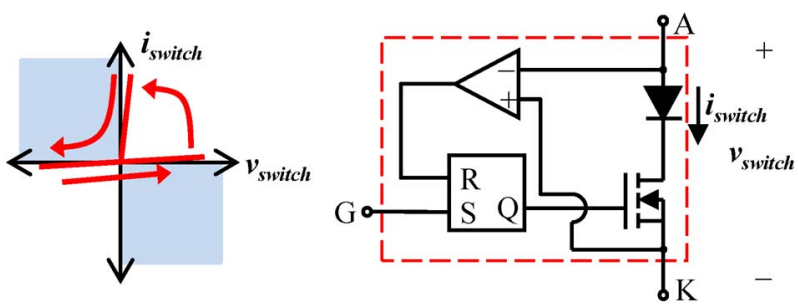

Fig. 11. Principle of the high-frequency thyristor.

\section{High-Frequency Thyristor}

After analyzing the current-mode converter, electric waveforms for the three switches reveal that each one of these switches present unidirectional current and bidirectional voltage; together with the switching conditions, one recognizes the characteristic of a thyristor, as shown in Fig. 11 (left). Nevertheless, these switches have to operate outside the typical frequency range available for commercial devices of this type.

For this reason, the solution proposed and implemented for this converter [35] can be appreciated in Fig. 11 (right). It consists of the series connection of a metal-oxide-semiconductor field-effect transistor and a fast diode. The turn-on of the thyristor is enabled when the anode-to-cathode voltage is positive and realized via the set input of an SR flip-flop. The turn-off is spontaneous when the diode blocks at zero current and the thyristor voltage becomes negative, performing a reset to the flip-flop: this locks the switch, avoiding the current flow if the thyristor voltage returns to positive values.

\section{Transformer}

The step-up transformer is essential to reduce the voltage of the lamp to the semiconductor device range. The configuration consisting of two primaries and one secondary winding has been chosen, in order to simplify the current inverter to a structure with only two common-cathode and ground-referenced thyristors.

This transformer requires a very special construction, as the lamp capacitance is on the order of $55 \mathrm{pF}$ : the power transfer to the lamp is indeed dramatically reduced if the parasitic capacitance of the secondary winding of the transformer matches a comparable value. Additionally, the magnetizing inductance must be maximized, and the leakage inductance must be minimized, to prevent a nonzero value for lamp current during the relaxation time and high-frequency oscillations during the discharge sequence, respectively.

The transformer is implemented using two " $U$ " cores; a single layer in the secondary side was chosen. In this way, the parasitic capacitance is reduced $(\sim 10 \mathrm{pF})$, with a high-enough magnetizing inductance ( $\sim 700 \mathrm{mH}$ in the secondary side). The primary and secondary windings are on the same leg in order to reduce the leakage inductance.

\section{E. Experimental Results}

The implementation of the current-mode converter is made with the values displayed in Fig. 12. This converter has been tested with a $60-\mathrm{W} \mathrm{XeCl} \mathrm{exciplex} \mathrm{lamp} \mathrm{from} \mathrm{Quantel} \mathrm{group.}$ 


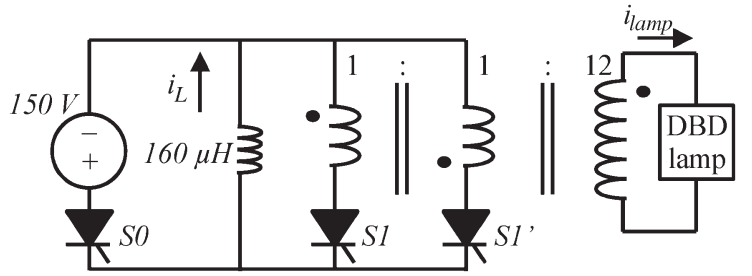

Fig. 12. Current-mode converter for DBD, based on the buck-boost topology.

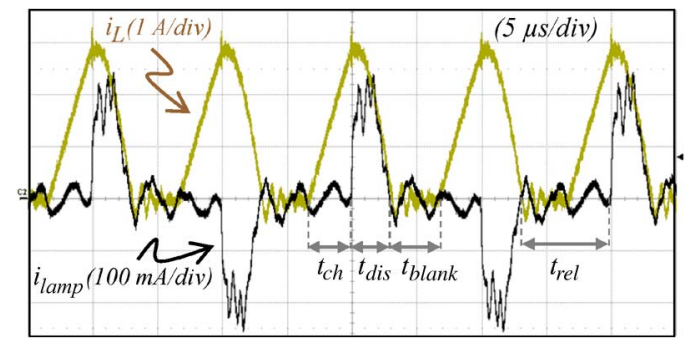

Fig. 13. Experimental results of the current-mode converter supplying a XeCl exciplex lamp.

This coaxial lamp, which was used for psoriasis treatment, is approximately $17 \mathrm{~cm}$ long, with inner and outer radii of 2 and $4 \mathrm{~cm}$, respectively, and silica thickness of $1.5 \mathrm{~mm}$.

Experimental results operating at $50 \mathrm{kHz}$ and $50 \mathrm{~W}$ in the lamp are shown in Fig 13. The measured values are in good accordance with (8)-(17).

The three different sequences presented in Section IV-B, i.e., charge, discharge, and blanking, can be clearly appreciated. In this figure, the lamp current (bidirectional waveform) presents some oscillations during the discharge sequence due to the parasitic elements of the transformer. Nevertheless, the current duration and amplitude is controlled by the switching circuit of the primary, as expected. The efficiency obtained for this converter is approximately $70 \%$; the power losses are mainly dissipated in the step-up transformer ( $\sim 63 \%$ of total losses).

\section{Power Control}

\section{A. Control of the Electrical Power}

The two DOFs offered by this current-mode converter, which is available to control the power delivered to the lamp, are illustrated in Fig. 14. For a given frequency, the energy sent to the lamp is changed using the value of $t_{\mathrm{ch}}$ [see (4) and (5)], and for each value, the instantaneous lamp power is computed with the measured waveforms of $i_{\text {lamp }}$ and $v_{\text {lamp }}$. Then, the same procedure is repeated for different frequencies.

As theoretically stated in Section IV-B, the power transferred to the lamp is shown to be controllable by means of these two DOFs [see (7)].

1) The pulse quantum energy is defined by $t_{\mathrm{ch}}$, which sets the energy stored in the inductance during the charge sequence: according to (4) and (5), it explains the quadratic shape of the characteristics of Fig. 14.

2) For a given pulse energy (i.e., a given charge time $t_{\mathrm{ch}}$ ), the lamp power also increases with the operating frequency of the converter.

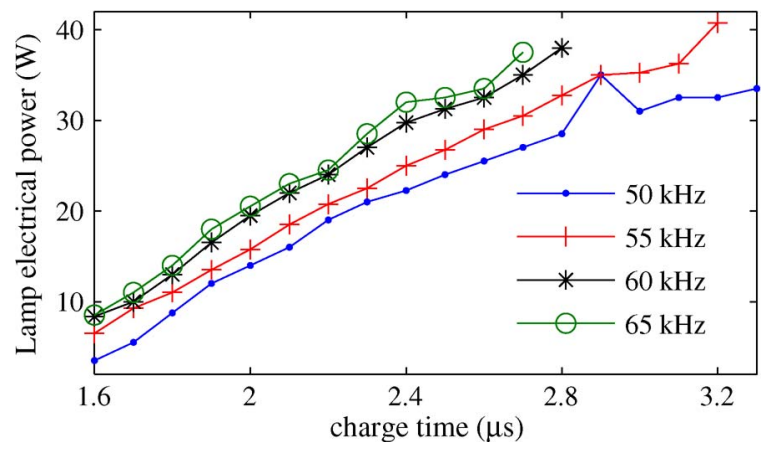

Fig. 14. Control of the electrical power in the lamp: increase of the power with the energy sent to the lamp and with the switching frequency.

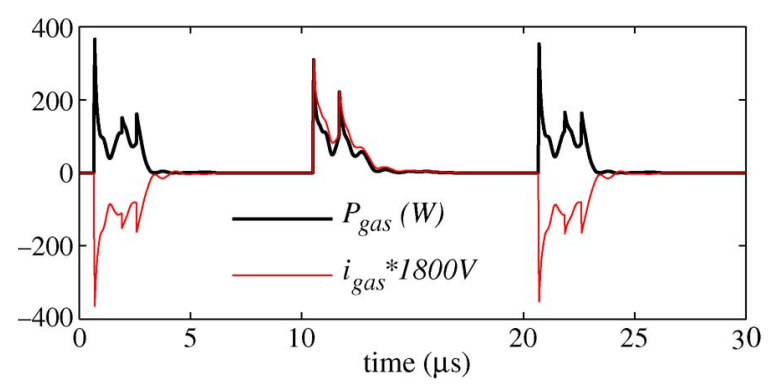

Fig. 15. Gas current and power. These two immeasurable variables are obtained using the model of the lamp and the experimental lamp current.

Additionally, to control the mean power of the lamp, the model developed in [20] makes possible the calculation of the gas variables, which are not measurable, taking the lamp current waveform as an input for simulation. This is very useful in analyzing the performances of the current control and validating the assumptions concerning the operating area of the gas discharge.

Gas power and gas current are both plotted in Fig. 15. These immeasurable variables are calculated by means of the identified lamp model taking the experimental lamp current as input. It is found that the two waveforms have a similar aspect, which means that power is effectively controlled by the gas current (with this last directly depending of the lamp current) and that gas voltage is almost constant and is equals to $V_{\text {th }}$ $(1800 \mathrm{~V})$.

\section{B. Control of the UV Radiation}

The experimental results presented in the previous section demonstrate the control of the electrical power in the lamp. On this basis, experiments are now carried out to determine how the current-mode converter manages the UV emission of the lamp.

1) UV Mean Power: To measure the UV emission of the lamp, a radiometer in the band of $308 \mathrm{~nm}$ (emission corresponding to the $\mathrm{XeCl}$ exciplex) is used. Its distance to the lamp is kept constant, as the measurements (in milliwatts per square centimeter) are relative to the distance at which those are taken.

As done previously, the energy in the lamp is varied at a fixed frequency, and then, the procedure is repeated for different frequencies. Results of this experiment are shown in Fig. 16.

Note that UV radiation is controlled correctly by the currentmode converter, using the two DOFs, i.e., energy and frequency 


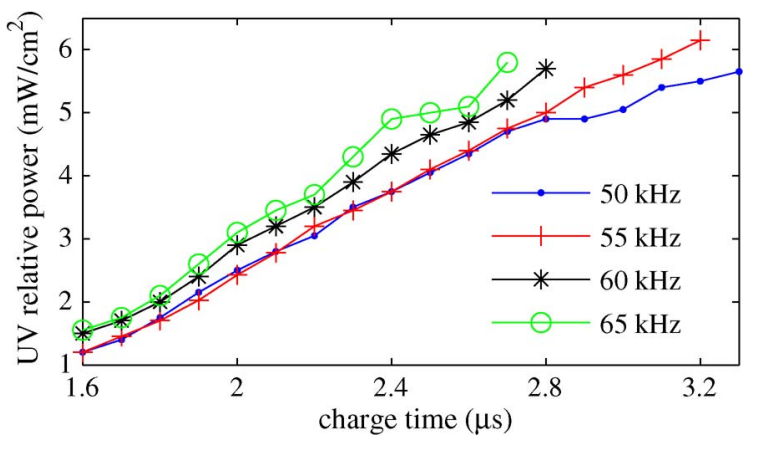

Fig. 16. Control of the radiation of the lamp by the current-mode power supply. The UV emission can be changed with 2 DOFs, i.e., frequency and energy (with the latter controlled by the charge time). Measurements are taken with a $308-\mathrm{nm}$ radiometer at $5 \mathrm{~cm}$ from the lamp.

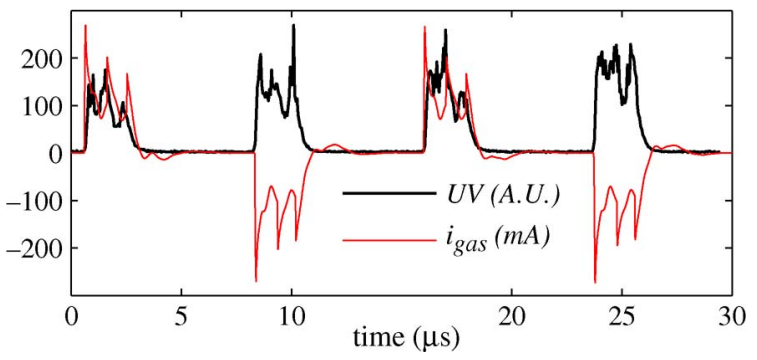

Fig. 17. UV radiation measured controlled by the gas current (calculated).

variation. Results are similar to those presented for the electrical power (cf. Fig. 14). Nevertheless, the lower curve at $50 \mathrm{kHz}$ has approached that at $55 \mathrm{kHz}$. This can be interpreted as better conversion, from electrical to optical power (higher efficiency), of the lamp at $50 \mathrm{kHz}$.

The last result is very interesting, letting it known that the current-mode power supply can be used to identify the optimal operating frequency of the lamp.

2) UV Instantaneous Power: The instantaneous power radiated by the lamp is measured with a set-up consisting on a high-speed camera and a monochromator adjusted at $308 \mathrm{~nm}$. This time-solved UV measurement is synchronized with the oscilloscope in order to compare the emitted power and the electric power transfer into the lamp.

Using the measured lamp current and by means of the electrical model, the gas voltage and current are computed. As expected, the gas voltage is almost constant. This means that the electrical gas power is directly controlled by the gas current.

In Fig. 17, the emitted UV power is compared, at the same time scale as that on synchronized waveforms, with the gas current (very similar to the current imposed into the lamp). It is possible to appreciate the correlation between both waveforms, denoting that the lamp power is actually controlled by the gas current. As a matter of fact, if a step is applied to the system, changing the charge time (energy) abruptly, the response obtained is a step in the UV emission.

\section{Conclusion and Perspectives}

The current-mode converter has been presented as an alternative to supply DBDs and particularly excimer lamps. This converter offers two DOFs to control the lamp power by means of the operating frequency and the energy injected to the lamp each half-period.

The radiation of the lamp can be instantaneously controlled by adjusting the amplitude and duration of the gas current. The current-mode converter offers this possibility and exhibits this advantage against the typical voltage-mode converters.

The presented converter structure based on the buck-boost converter was analyzed using the state plane in order to establish the electric variables and the discharge time.

Additional work can be done, a parametric variation of the two DOFs could improve the electric-to-UV efficiency, identifying the optimal operating point.

In the future, the converter efficiency could be considerably increased, particularly focusing on the optimization of the highvoltage transformer, which has experimentally shown to be the major cause of losses, combining the control of its parasitic elements, together with efficiency improvements.

\section{ACKNOWLEDGMENT}

The authors would like to thank J.-M. Blaquière for his collaboration with the power converter implementation and Dermoptics (Quantel Group) for providing their patented lamp.

\section{REFERENCES}

[1] U. Kogelschatz, "Dielectric-barrier discharges: Their history, discharge physics, and industrial applications," Plasma Chem. Plasma Process., vol. 23 , no. 1, pp. 1-46, Mar. 2003.

[2] C. Zhang, T. Shao, K. Long, Y. Yu, J. Wang, D. Zhang, P. Yan, and Y. Zhou, "Surface treatment of polyethylene terephthalate films using DBD excited by repetitive unipolar nanosecond pulses in air at atmospheric pressure," IEEE Trans. Plasma Sci., vol. 38, no. 6, pp. 1517-1526, Jun. 2010.

[3] N. De Geyter, R. Morent, and C. Leys, "Pressure dependence of helium DBD plasma penetration into textile layers," IEEE Trans. Plasma Sci., vol. 36, no. 4, pp. 1308-1309, Aug. 2008.

[4] G. Vezzu, J. L. Lopez, A. Freilich, and K. H. Becker, "Optimization of large-scale ozone generators," IEEE Trans. Plasma Sci., vol. 37, no. 6, pp. 890-896, Jun. 2009.

[5] M. I. Lomaev, E. A. Sosnin, V. F. Tarasenko, D. V. Shits, V. S. Skakun, M. V. Erofeev, and A. A. Lisenko, "Capacitive and barrier discharge excilamps and their applications (review)," Instrum. Exp. Tech., vol. 49, no. 5, pp. 595-616, Oct. 2006.

[6] E. A. Sosnin, S. M. Avdeev, E. A. Kuznetzova, and L. V. Lavrent'eva, "A bactericidal barrier-discharge $\mathrm{KrBr}$ excilamp," Instrum. Exp. Tech., vol. 48, no. 5, pp. 663-666, Sep. 2005.

[7] M. V. Erofeev, I. E. Kieft, E. A. Sosnin, and E. Stoffels, "UV excimer lamp irradiation of fibroblasts: The influence on antioxidant homeostasis," IEEE Trans. Plasma Sci., vol. 34, no. 4, pp. 1359-1364, Aug. 2006.

[8] M. M. Guivan, T. Kamikozawa, H. Kurokawa, H. Motomura, K. Kadowaki, and M. Jinno, "Comparative inactivation of Bacillus subtilis spores using a DBD-driven xenon iodide excilamp and a conventional mercury lamp," IEEE Trans. Plasma Sci., vol. 38, no. 8, pp. 1972-1977, Aug. 2010.

[9] E. A. Sosnin, T. Oppenländer, and V. F. Tarasenko, "Applications of capacitive and barrier discharge excilamps in photoscience," J. Photochem. Photobiol. C, Rev., vol. 7, no. 4, pp. 145-163, Dec. 2006.

[10] J.-Y. Zhang and I. W. Boyd, "Low temperature photo-oxidation of silicon using a xenon excimer lamp," Appl. Phys. Lett., vol. 71, no. 20, pp. 2964-2966, Nov. 1997.

[11] J.-Y. Zhang and I. W. Boyd, "Lifetime investigation of excimer UV sources," Appl. Surf. Sci., vol. 168, no. 1-4, pp. 296-299, Dec. 2000.

[12] J. Kunze, N. Frohleke, H. Grotstollen, B. Margaritis, and F. Locken, "Resonant power supply for barrier discharge UV-excimer sources," in Conf. Rec. IEEE IAS Annu. Meeting, Oct. 4-9, 1992, vol. 1, pp. 750-753.

[13] S.-Y. Lee, J.-S. Gho, B.-H. Kang, and J.-S. Cho, "Analysis of pulse power converter for plasma application," in Proc. IEEE IECON, Nov. 10-13, 2008, pp. 556-560. 
[14] J. M. Alonso, C. Ordiz, M. A. Dalla Costa, J. Ribas, and J. Cardesin, "High-voltage power supply for ozone generation based on piezoelectric transformer," IEEE Trans. Ind. Appl., vol. 45, no. 4, pp. 1513-1523, Jul./Aug. 2009.

[15] K. Kyrberg, H. Guldner, A. Rupp, and O. Schallmoser, "Half-bridge and full-bridge choke converter concepts for the pulsed operation of large dielectric barrier discharge lamps," IEEE Trans. Power Electron., vol. 22, no. 3, pp. 926-933, May 2007.

[16] M. A. Dalla Costa, J. M. Alonso, J. C. Miranda, J. Garcia, and D. G. Lamar, "A single-stage high-power-factor electronic ballast based on integrated buck flyback converter to supply metal halide lamps," IEEE Trans. Ind. Electron., vol. 55, no. 3, pp. 1112-1122, Mar. 2008.

[17] M. S. Perdigao, J. M. Alonso, M. A. Dalla Costa, and E. S. Saraiva, "Comparative analysis and experiments of resonant tanks for magnetically controlled electronic ballasts," IEEE Trans. Ind. Electron., vol. 55, no. 9, pp. 3201-3211, Sep. 2008.

[18] R. O. Sanchez, N. Vazquez, C. Hernandez, E. Rodriguez, S. Pinto, and M. Juarez, "Electric dynamic modeling of HID lamps for electronic ballast design," IEEE Trans. Ind. Electron., vol. 57, no. 5, pp. 1655-1662, May 2010.

[19] T.-E. Jang, H.-J. Kim, and H. Kim, "Dimming control characteristics of electrodeless fluorescent lamps," IEEE Trans. Ind. Electron., vol. 56, no. 1, pp. 93-100, Jan. 2009.

[20] R. Díez, J.-P. Salanne, H. Piquet, S. Bhosle, and G. Zissis, "Predictive model of a DBD lamp for power supply design and method for the automatic identification of its parameters," Eur. Phys. J. Appl. Phys., vol. 37, no. 3, pp. 307-313, Mar. 2007.

[21] B. Rahmani, S. Bhosle, and G. Zissis, "Dielectric-barrier-discharge excilamp in mixtures of krypton and molecular chlorine," IEEE Trans. Plasma Sci., vol. 37, no. 4, pp. 546-550, Apr. 2009

[22] R. P. Mildren, R. J. Carman, and I. S. Falconer, "Visible and VUV emission from a xenon dielectric barrier discharge using pulsed and sinusoidal voltage excitation waveforms," IEEE Trans. Plasma Sci., vol. 30, no. 1, pp. 192-193, Feb. 2002.

[23] J. M. Alonso, J. Cardesin, E. L. Corominas, M. Rico-Secades, and J. Garcia, "Low-power high-voltage high-frequency power supply for ozone generation," IEEE Trans. Ind. Appl., vol. 40, no. 2, pp. 414-421, Mar./Apr. 2004

[24] S. Ben-Yaakov and M. M. Peretz, "A self-adjusting sinusoidal power source suitable for driving capacitive loads," IEEE Trans. Power Electron., vol. 21, no. 4, pp. 890-898, Jul. 2006.

[25] S. Rampen, S. W. H. de Haan, R. B. Dill, B. Roodenburg, Y. L. M. Creyghton, and J. A. Ferreira, "Series resonance power supply for dielectric barrier reactor," in Proc. 11th Int. EPE-PEMC, 2004, pp. 1-7.

[26] S. W. H. de Haan, B. Roodenburg, Y. L. M. Creyghton, A. Fiala, and T. Huijser, "High-voltage pulsed-power supplies for automotive exhaust gas treatment with dielectric barrier reactor," in Proc. 13th Int. Symp. High Voltage Eng., Delft, The Netherlands, 2003, pp. 171-174.

[27] J. M. Alonso, J. Garcia, A. J. Calleja, J. Ribas, and J. Cardesin, "Analysis, design, and experimentation of a high-voltage power supply for ozone generation based on current-fed parallel-resonant pushpull inverter," IEEE Trans. Ind. Appl., vol. 41, no. 5, pp. 1364-1372, Sep./Oct. 2005.

[28] S. M. Avdeev, I. D. Kostyrya, E. A. Sosnin, and V. F. Tarasenko, "Generation of nanosecond pulses in a barrier-discharge $\mathrm{XeBr}$ excimer lamp," Tech. Phys., vol. 51, no. 7, pp. 878-881, Jul. 2006.

[29] R. P. Mildren and R. J. Carman, "Enhanced performance of a dielectric barrier discharge lamp using short-pulsed excitation," J. Phys. D, Appl. Phys., vol. 34, no. 1, pp. L1-L6, Jan. 2001.

[30] R. J. Carman and R. P. Mildren, "Computer modelling of a shortpulse excited dielectric barrier discharge xenon excimer lamp (172 nm)," J. Phys. D, Appl. Phys., vol. 36, no. 1, pp. 19-33, Jan. 2003.

[31] A. Oda, H. Sugawara, Y. Sakai, and H. Akashi, "Estimation of the light output power and efficiency of Xe barrier discharge excimer lamps using one-dimensional fluid model for various voltage waveforms," J. Phys. D, Appl. Phys., vol. 33, no. 12, pp. 1507-1513, Jun. 2000.

[32] R. Oruganti and F. C. Lee, "Resonant power processors, part I-State plane analysis," IEEE Trans. Ind. Appl., vol. IA-21, no. 6, pp. 1453-1460, Nov. 1985

[33] Y. Cheron, Soft Commutation. London, U.K.: Chapman \& Hall, 1992.

[34] R. Diez, H. Piquet, S. Bhosle, and J.-M. Blaquière, "Current mode converter for dielectric barrier discharge lamp," in Proc. IEEE Power Electron. Spec. Conf., Jun. 2008, pp. 2485-2491.

[35] M. Cousineau, R. Díez, H. Piquet, and O. Durieu, "Synthesised highfrequency thyristor for dielectric barrier discharge excimer lamps," IEEE Trans. Ind. Electron., to be published.

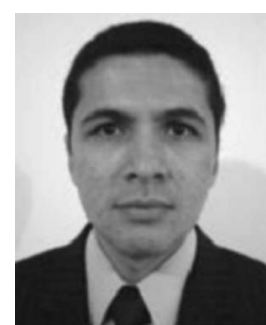

Rafael Díez (M'10) received the B.E. degree in electronics engineering from Pontificia Universidad Javeriana, Bogotá, Colombia, in 2001 and the M.Sc. degree in microelectronics and the $\mathrm{Ph} . \mathrm{D}$. degree in electrical engineering from Université de Toulouse, Toulouse, France, in 2005 and 2008, respectively.

$\mathrm{He}$ is currently with the Department of Electronics, Pontificia Universidad Javeriana. His research interest is the development of power converters for electric discharges.

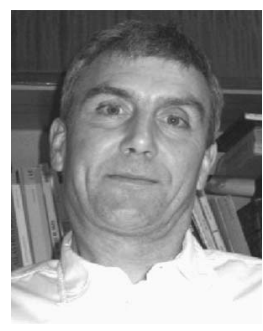

Hubert Piquet received the B.S. degree in applied physics from Ecole Normale Supérieure de Cachan, Cachan, France, in 1984 and the Ph.D. degree in electrical engineering from Institut National Polytechnique de Toulouse, Toulouse, France, in 1990.

$\mathrm{He}$ is currently a Professor with ENSEEIHT Engineering School, Toulouse, where he teaches power electronics. His research activity takes place in Laboratoire PLAsma et Conversion d'Energie (LAPLACE), Toulouse. His research interests include quality and stability in embedded networks and power supplies for electrical discharge applications

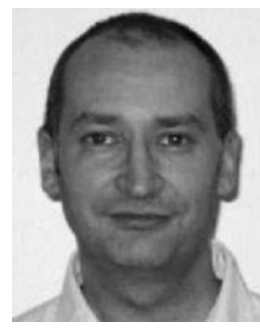

Marc Cousineau (M'96) received the B.E. degree in electrical engineering and the Ph.D. degree from Institut National Polytechnique de Toulouse, Toulouse, France, in 1995 and 1999, respectively.

$\mathrm{He}$ is currently a Professor Assistant with ENSEEIHT Engineering School, Toulouse. His research activity takes place in Laboratoire PLAsma et Conversion d'Energie (LAPLACE), Toulouse. His research interests include high-voltage integrated circuit design for power electronic applications and static converter modeling and control.

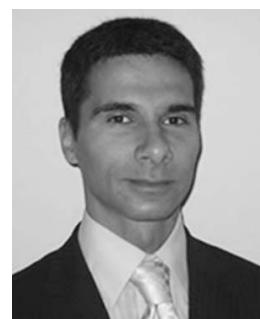

Sounil Bhosle (M'00) was born in Poitiers, France, in 1972 . He received the B.Sc. degree in physics from Poitiers University, Poitiers, in 1996 and the M.S. and Ph.D. degrees in plasma science from Toulouse 3 University, Toulouse, France, in 2001 and 2006, respectively.

$\mathrm{He}$ is a Specialist on dielectric barrier discharge lamps. From 1997 to 2009, he occupied a position in the LAboratoire PLAsma et Conversion d'Energie (LAPLACE), Toulouse. He is currently a Research and Development Engineer with the LED Engineering Development, Ramonville, France, keeping the status of Associate Researcher at LAPLACE. He authored/coauthored more than 20 papers in international journals and conference proceedings.

Dr. Bhosle is currently the Chair of the Industrial Lighting and Display Committee of the IEEE Industry Applications Society. He has been the Secretary of the regional branch of the French Illuminating Society. 